Research Paper:

\title{
The Psychometric Properties of Health Literacy for Iranian Adults (HELIA) in Medical Sciences Students
}

\author{
Rahman Panahi ${ }^{1}$ (D, Ali Ramezankhani² (D, Mahmoud Tavousi ${ }^{3}$ (D), Aliasghar Haeri Mehrizi ${ }^{4}$ (D), Shamsaddin Niknami5 ${ }^{*}$ (D) \\ 1. Department of Health Education and Promotion, School of Medical Sciences, Tarbiat Modares University, Tehran, Iran. \\ 2. Department of Health Services, Shahid Beheshti University of Medical Sciences Tehran, Iran. \\ 3. Health Metrics Research Center, Iranian Institute for Health Sciences Research, ACECR, Tehran, Iran. \\ 4. Health Metrics Research Center, Iranian Institute for Health Sciences Research, ACECR, Tehran, Iran. \\ 5. Department of Health Education and Health Promotion, School of Medical Sciences, Tarbiat Modares University, Tehran, Iran.
}

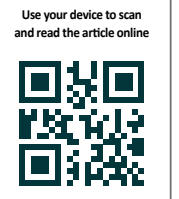

Cftation Panahi R, Ramezankhani A, Tavousi M, Haeri Mehrizi AA, Niknami Sh. The Psychometric Properties of Health Literacy for Iranian Adults (HELIA) in Medical Sciences Students. Journal of Research \& Health. 2020; 10(1):53-58. http:// dx.doi.org/10.32598/JRH.10.1.53

http://dx.doi.org/10.32598/JRH.10.1.53

Keywords:

Health literacy, University students, Psychometric, Health Literacy for Iranian Adults (HELIA)

\begin{abstract}
A B S T R A C T
Background: Despite the existence of numerous tools to measure health literacy, there is no general agreement on this issue. Researchers around the world have been involved in the development of an instrument to measure health literacy. The psychometric properties of the Health Literacy for Iranian Adults (HELIA) scale have been approved in the general population; however, the validity and reliability of this indigenous questionnaire has not been explored in students. Therefore, due to demographic differences, the present study investigated this questionnaire in a sample of students for structural validity and reliability.
\end{abstract}

Methods: This cross-sectional study was conducted on 340 dormitory students of Shahid Beheshti University of Medical Sciences in 2016, in Tehran City, Iran. A single-stage cluster sampling technique was used for sampling. Cronbach's alpha coefficient was used to verify the reliability of the questionnaire and the confirmatory factor analysis was used to investigate the validity of the constructs by LISREL software.

Results: The Mean $\pm \mathrm{SD}$ age of studied students was $22.93 \pm 4.05$ years. The questionnaire had a desirable internal consistency (Cronbach's alpha coefficient: 0.77-0.90) to assess health literacy in participating students. The confirmatory factor analysis result was satisfactory for its overall fitness. (RMSEA $=0.095, \mathrm{CFI}=0.94, \mathrm{NFI}=0.92, \mathrm{NNFI}=0.94, \mathrm{SRMR}=0.075, \mathrm{X}^{2} / \mathrm{df}=4.09$ ).

Conclusion: The study findings revealed that HELIA is a reliable and valid instrument for measuring health literacy among students.

\footnotetext{
* Corresponding Author:

Shamsaddin Niknami, PhD.

Address: Department of Health Education and Health Promotion, School of Medical Sciences, Tarbiat Modares University, Tehran, Iran

Phone: +98 (21) 82883549 .

E-mail:niknamis@modares.ac.ir
} 


\section{Introduction}

ealth literacy can be defined as the ability to accessing, understanding, appraise, $\mathbf{H}$ and transmit information through the promotion, maintenance, and improvement of health in various life aspects [1]. Nutbeam argues that health literacy is a crucial implication of health education interventions; it should be addressed in the broader sense of health promotion. Moreover, health promotion authorities should pay more attention to this concept [2].

Health literacy is a fundamental basis for the health and life of modern citizenship. Furthermore, it is a vital combination of social capital that should be considered in all sectors (not only in the health sector) [3]. The American Institute of Medicine, in its first report about health literacy, declared that knowledge, skills, and health behaviors are significantly influenced by three categories of "cultural context, health system requests, and previous learning opportunities" in individuals. In this report, limited health literacy is not only a problem for individuals but also a challenge for healthcare providers who need to overcome them and communicate more effectively with patients [4]. It is unclear how health literacy affects health outcomes; however, many reasons suggest that numerous health-related outcomes are due to inadequate health literacy [5]. Despite the great importance of health literacy, this issue has been overlooked in Iran. The need to address this issue and its dimensions can serve as an effective indicator for planners and officials [6].

The design of health literacy measurement tool has recently attracted health researchers' attention around the world. In this regard, essential measures have been taken, especially in the design, testing, and use of screening tools [7]; however, there is no consensus about various tools in this regard [8-12]. Literacy level depends on individual characteristics and the contact level of people have with the health system; thus, different tools are required for different age groups and different life stages. Health literacy level and the required information of pregnant woman is quite different from a person who has recently been diagnosed with type 2 diabetes; this should be considered in measuring health literacy $[12,13]$.

According to the concepts and provided definitions of health literacy, various tools, such as the Parent Health Literacy Action Test (PHLAT), Rapid Estimate of Adult Literacy in Medicine (REALEM), the Oral Health Literacy Inventory (OHLI), etc. are being developed and evaluated psychometrically in different countries. Health
Literacy for Iranian Adults (HELIA) (18-65 years) is the first indigenous tool for measuring health literacy in Iran, developed by Montazeri and colleagues [14]. The psychometric properties of this tool have been established in the general population $[15,16]$; however, its validity and reliability remain unrecognized among students. Therefore, given the existence of demographic differences, the current study evaluated the psychometric properties of the above-mentioned questionnaire in a sample of students in terms of structural validity and reliability.

\section{Methods}

This descriptive-analytical study was conducted in the dormitory students of Shahid Beheshti University of Medical Sciences in Tehran City, Iran, during the second semester of the 2015-2016 academic year. Students participating in this study were selected through a singlestage cluster sampling method; first, the list of all dormitories was provided were medical students in various fields lived. Then, 4 dormitories ( 2 for girls and 2 for boys) were randomly selected. Next, study participants were recruited per the study inclusion criteria.

The inclusion criteria included the willingness to participate in the study, being an undergraduate student, being in the second or third year of the university course, having Iranian citizenship, and residency in dormitories under the supervision of Shahid Beheshti University of Medical Sciences. Additionally, unwillingness to continue to participate in the study and failure to complete the questionnaire was considered as the exclusion criteria.

Hair et al., for sample size estimation for factor analysis, recommended minimum sample size of 5 samples and a maximum of 20 samples per goblet [17]. Finally, considering that the tool had 33 items, for each item, 10 samples were considered; therefore, the sample size should be considered equal to 330 individuals [18]. However, by taking $10 \%$ of the samples, 365 people were eventually included in the study.

Having a uniform structure and incorporating various dimensions of the HELIA questionnaire has many easy-to-use functions in the general population [16]. The questionnaire consists of 5 main dimensions of reading (4 items), accessing (6 items), understanding (7 items), appraisal (4 items), as well as decision making and applying health information (12 items) [14].

Cronbach's alpha coefficient was used to determine the construct validity of the scale. Confirmatory factor analysis was used in LISREL software. Regarding the fitting 
indexes in the factor analysis, for the degree of freedom ( $\mathrm{X}^{2} / \mathrm{df}$ ), the Chi-squared is $<3$, although some of them with values of 4 , and even 5 are considered proper for fit [19]. The rate of other indicators used in LISREL, such as the Normal Fit Index (NFI), Non-Normal Fitness Index (NNFI), Adequacy Fitness Index (CFI), and Fit Fitness Index (GFI), range from zero to one; values closer to one indicate better fit than the pattern [20]. Other fitting indices include a Root Mean Square Estimation Error (RMSEA) with an acceptable value of maximum 0.1 and a Standardized Residual Median Root (SRMR) index with an acceptable value of maximum 0.08 [21-23].

\section{Results}

A total of 340 students with the Mean \pm SD age of $22.93 \pm 4.05$ years participated in the study. Moreover, 25 students were excluded (response rate:93.2\%). Of these, 204 (60\%) were girls, and 136 (40\%) were boys. Furthermore, 199 (59\%) students were third-year students and 141 (41\%) were second-year students. Figure 1 shows the confirmation of the structure of the questionnaire and its relation to the 5 dimensions of the questionnaire. Table 1 lists fitness indexes in confirmatory factor analysis of the HELIA questionnaire. Due to the smaller index of RMSEA $(<0.1)$, the SRMR is $<0.08$, the $\mathrm{X}^{2} /$ df index is $<5$, and the NFI, NNFI, and CFI indexes are $>0.9$, which approved the validity of the tool. In addition, the Cronbach's alpha coefficient for each dimension and the total tool was acceptable in the study subjects (Cronbach's alpha=0.7) (Table 2).

\section{Discussion}

This study aimed to explore the psychometric properties of the HELIA questionnaire among a sample of students of Shahid Beheshti University of Medical Sciences. The study findings revealed that in terms of internal correlation, various factors of the HELIA questionnaire had high internal consistency ( 0.77 to 0.90$)$; this finding was consistent with that of Montazeri et al. [14]. They reported Cronbach's alpha coefficient between 0.72 and 0.89 . Moreover, it was in line with the study by Haeri Mehrizi et al. who documented a Cronbach's alpha of 0.67-0.93 [15]. In addition, our obtained data were consistent with those of the study by Zareban et al. who suggested Cronbach's alpha between 0.78 and 0.90 [16]. Besides, the results of Taheri and Mahmoudi [24] and Ebrahimpour et al. [25] were in line with ours; they reported Cronbach's alpha coefficients of 0.86 and 0.98 , respectively for the total questionnaire.

The confirmatory factor analysis results confirmed the structure of the HELIA questionnaire. The values of standardized parameters indicate the factor load power of each question on its subscale factor. Moreover, it reflects that each question explains what proportion of the subsample variance. Without considering of load factor, it explains the better variance; in sum, these factor loads suggest the variance of each sub-equation [16]. Therefore, the questions of each subscale are appropriately selected and can be evaluated by 5 hidden variables of the questionnaire, including accessing, reading, understanding, appraisal, as well as decision-making and imple-

Table 1. Fit fittings in confirmatory factor analysis of HELIA questionnaire

\begin{tabular}{ccccccc}
\hline Index & $\mathbf{X}^{2} / \mathrm{df}$ & CFI & NNFI & NFI & SRMR & RMSEA \\
\hline Amount & 4.09 & $0.94 \mathrm{~s}$ & 0.94 & 0.92 & 0.075 & 0.095 \\
Acceptable amount & $<5$ & $>0.90$ & $>0.90$ & $>0.90$ & $<0.08$ & $<0.1$ \\
\hline
\end{tabular}

Table 2. Cronbach's alpha coefficients for the total and dimensions of HELIA questionnaire

\begin{tabular}{cc}
\hline Dimensions & Cronbach's Alpha Coefficients \\
\hline Reading & 0.84 \\
\hline Accessing & 0.85 \\
\hline Understanding & 0.90 \\
Appraisal & 0.77 \\
\hline Decision-making and appying health information & 0.86 \\
\hline Total & 0.94 \\
\hline
\end{tabular}




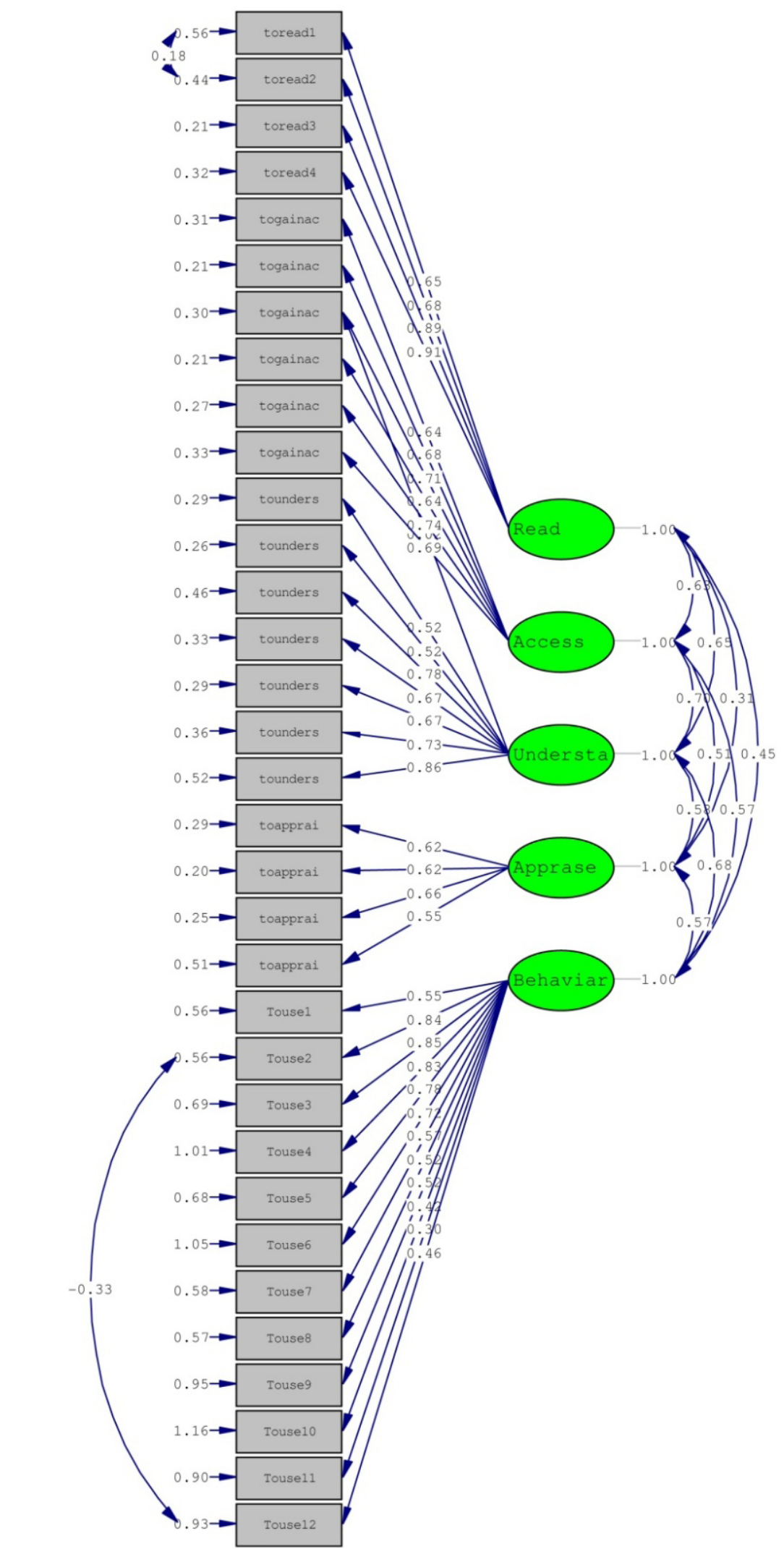

Chi-Square $=1970.54, d f=482, \quad P-$ value $=0.00000$, RMSEA $=0.095$

Figure 1. An overview of confirmatory factor structure by the LISREL among the study sample 
menting health information. The findings of this section were consistent with those of Haeri Mehrizi et al. [15] and Zareban et al. [16]. The survey fit indices in the HELIA questionnaire revealed that this 5-factor model has a suitable fit. These findings were consistent with those of Zareban et al. [16] and Haeri Mehrizi et al. [15].

To our knowledge, this study was the first to examine the factor analysis of this questionnaire among students. Given that this study was conducted only among undergraduate medical sciences students who live in a dormitory, it may not be generalized to all students. Therefore, to increase the generalizability of the achieved results, it is necessary to evaluate the tool among post-graduate, non-dormant and non-medical students.

\section{Conclusion}

The obtained results indicated that the HELIA questionnaire could be used in the student population.

\section{Ethical Considerations}

\section{Compliance with ethical guidelines}

Ethical approval was received from the ethics committee of the Tarbiat Modares University (ID: IR.TMU.REC.1394.172, Date: December 19, 2015). The aims and procedures of the study were explained to the participants. Anonymity and confidentiality of the study were assured and then the participants signed informed consent letters.

\section{Funding}

The authors received no financial support for the research, authorship, and/or publication of this article.

\section{Authors' contributions}

Study design: Rahman Panahi, Shamsaddin Niknami, Ali Ramezankhani, Mahmoud Tavousi; Data collection and analysis: Rahman Panahi, Mahmoud Tavousi, Aliasghar Haeri Mehrizi; Manuscript preparation: Rahman Panahi, Shamsaddin Niknami, Ali Ramezankhani, Mahmoud Tavousi, Aliasghar Haeri Mehrizi.

\section{Conflict of interest}

The authors declared no competing interests.

\section{References}

[1] Rootman I, Gordon-El-Bihbety D. A Vision for a Health Literate Canada. Report of the expert panel on health literacy. Ottawa ON: Canadian Public Health Association; 2008.

[2] Kanj M, Mitic W. Health literacy and health promotion definitions, concepts and examples in the eastern mediterranean region. Paper presented at: $7^{\text {th }}$ Global Conference on Health Promotion, "Promoting Health and Development: Closing the Implementation Gap". 2009: Nairobi: Republic of Kenya.

[3] Rubin DL, Parmer J, Freimuth V, Kaley T, Okundaye M. Associations between older adults' spoken interactive health literacy and selected health care and health communication outcomes. J Health Commun. 2011; 16(Suppl. 3):191-204. [D OI:10.1080/10810730.2011.604380] [PMID]

[4] Paasche-Orlow MK, Wolf MS. Promoting health literacy research to reduce health disparities. J Health Commun. 2010; 15(Suppl. 2):34-41. [DOI:10.1080/10810730.2010.49999 4] [PMID]

[5] Williams MV, Parker RM, Baker DW, Coates W, Nurss J. The impact of inadequate functional health literacy on patients' understanding of diagnosis, prescribed medications, and compliance. Acad Emerg Med. 1995; 2:386.

[6] Tehrani Banihashemi SA, Amirkhani MA, Haghdoost AA, Alavian SM, Asgharifard H, Baradaran H, et al. Health literacy and the influencing factors: A study in five provinces of Iran. [Internet]. 2007. Available from: https://www. researchgate.net/publication/269349703_Health_Literacy_and_the_Influencing_Factors_A_Study_in_Five_Provinces_of_Ira

[7] Abel T. Measuring health literacy: Moving towards a healthpromotion perspective. Int J Public Health 2008; 53(4):169-70. [DOI:10.1007/s00038-008-0242-9] [PMID]

[8] Baker DW. The meaning and the measure of health literacy. J Gen Intern Med. 2006; 21(8):878-83. [DOI:10.1111/j.15251497.2006.00540.x] [PMID] [PMCID]

[9] Baker DW, Williams MV, Parker RM, Gazmararian JA, Nurss J. Development of a brief test to measure functional health literacy. Patient Educ Couns. 1999; 38(1):33-42. [DOI:10.1016/S0738-3991(98)00116-5]

[10] Begoray DL, Kwan B. A Canadian exploratory study to define a measure of health literacy. Health Promot Int. 2012; 27(1):23-32. [DOI:10.1093/heapro/dar015] [PMID]

[11] Buchbinder R, Batterham R, Ciciriello S, Newman S, Horgan $B$, Ueffing E, et al. Health Literacy: What Is It and Why Is It Important to Measure? J Rheumatol. 2011; 38(8):1791-7. [DOI:10.3899/jrheum.110406] [PMID]

[12] Chisolm DJ, Buchanan L. Measuring adolescent functional health literacy: A pilot validation of the test of functional health literacy in adults. J Adolesc Health. 2007; 41(3):312-4. [DOI:10.1016/j.jadohealth.2007.04.015] [PMID]

[13] Fransen MP, Twickler TB, Essink-Bot ML. Health literacy measures: Application and implication. Eur J Public Health. 2010; 20:269.

[14] Montazeri A, Tavousi M, Rakhshani F, Azin seyed A, Jahangiri K, Ebadi M, et al. [Health Literacy for Iranian Adults (HELIA): Development and psychometric Properties (Persian)]. Payesh. 2014; 13:589-99. 
[15] Haeri Mehrizi AA, Tavousi M, Rafieifar SH, Soleimanian A, Sarbandi F, Ardestani MS, et al. [Health Literacy for Iranian Adults (HELIA): the confirmatory factor analysis (Persian)]. Payesh. 2016; 3:251-7.

[16] Zareban I, Izadirad H, Araban M. [Psychometric Evaluation of Health Literacy for Adults (HELIA) in urban area of Balochistan (Persian)]. Payesh. 2016; 6:669-76.

[17] Hair JF, Black WC, Babin BJ, Anderson RE. Multivariate data analysis. New Jersey: Prentice Hall; 2010.

[18] Hajizade E, Asghari M. Methods and statistical analysis looking at the methodology. Tehran: Press Agency SID; 2011.

[19] Munro BH. Statistical methods for health care research. $5^{\text {th }}$ Ed, UK: Lippincott Williams Wilkins; 2005.

[20] Hooman H. [Structural equation modeling with Lisrel application (Persian)]. $1^{\text {st }}$ Ed. Tehran: Samt; 2005.

[21] Mason ST, Arceneaux LL, Abouhassan W, Lauterbach D, Seebach C, Fauerbach JA. Confirmatory factoranalysis of the short form mcgill pain questionnaire with burn patients. Eplasty. 2008; 8:494-504.

[22] Hooper D, Coughlan J, Mullen MR. Structural equation model- ling: Guidelines for determiningmodel fit. Electron J Bus Res Methods. 2007; 6(1):53-60.

[23] Marsh HW, Hau K, Wen Z. In search of golden rules: comment on hypothesis testing approaches tosetting cut-off values for fit indexes and dangers in over generalizing $\mathrm{Hu}$ and Bentler's findings. Struct Equ Modeling. 2004; 11:320-41 [DOI:10.1207/s15328007sem1103_2]

[24] Mahmoudi H, Taheri A. [Relation between information literacy and health literacy of students in Ferdowsi university of Mashhad (Persian)]. Human Info Interact. 2015; 2(2):31-41.

[25] Ebrahimpour F, Azimian J, Hasandoost F, Rafiei H, Pelarak G. Effect of an educational program on level of health literacy among health care workers. Int J Novel Res Healthc Nurs. 2016; 3(2):220-24. 